\title{
Aspectos ReLEVANTES DA AVALIAÇÃO DOS CONTROLES INTERNOS NA AUDITORIA GOVERNAMENTAL
}

\author{
Roberto Sérgio do Nascimento \\ Graduado em Ciências Contábeis e Administração. Mestre em \\ Adminstração. Docente da Universidade Federal do Ceará - UFC e \\ Analista de Controle Externo do Tribunal de Contas da União. E- \\ mails: robertose@uol.com.br,robertosn@tcu.gov.br
}

\section{RESUMO}

A avaliação dos controles internos é atividade decisiva na realização dos trabalhos de auditoria. Primeiramente, contextualiza-se a auditoria nos tempos atuais, demonstrando que esta disciplina não representa mais o simples exame dos demonstrativos contábeis em contraposição aos registros da escrituração contábil. Vai além. Busca a consonância dos princípios fundamentais de contabilidade e das normas brasileiras de contabilidade, na medida que preserva a materialização adequada dos fenômenos que afetam à Ciência Contábil como um todo. À semelhança do modelo tradicional de auditoria, o auditor independente, interno ou governamental necessita conhecer a importância dos controles internos na salvaguarda do patrimônio, prevenção de fraudes, no registro correto das transações e na promoção da eficiência operacional. Contudo, a avaliação a ser efetivada deve levar em consideração que nem todos os controles são decisivos em termos de mutação patrimonial, como é o caso dos controles administrativos. Todas as organizações, quer sejam elas públicas ou privadas, possuem controles dos mais variados possíveis. No tocante à esfera estatal, percebe-se que o assunto ainda não foi totalmente explorado entre os motivos: uma da inexistência da sistematização desta análise, divulgação dos métodos de exame e conhecimento dos efeitos gerados sob o trabalho do auditor público. Assim, o artigo busca abordar alguns mecanismos de avaliação que podem ser utilizados por estes profissionais, tais como: relatório de situação, questionário, memorando de descrição e fluxograma.

Palavras-chave: Controle Interno, Auditoria, Avaliação, Administração Pública.

\section{ABSTRACT}

Evaluation of internal controls is a decisive activity in the performance of auditing tasks. Firstly, auditing is situated in the present day, demonstrating that this discipline no longer represents a mere examination of accounts compared with accounting records. It goes beyond that. Seeking consonance with the fundamental principles of accounting and Brazilian accounting norms, as it preserves appropriate materialization of phenomena which affect Accounting Sciences as a whole. The similarity of the traditional model of auditing, the independent auditor, both internal or governmental, must realize the importance of internal controls in safeguarding assets, prevention of frauds, correct recording of transactions and in promotion of operational efficiency. However, the assessment to be performed must consider that not all controls are decisive in terms of asset changes, as is the case with administrative controls. All organizations, whether public or private, have highly varied controls. With regard to the state sphere, one may note that the topic has not yet been fully explored, given the lack of a system for such analysis, dissemination of methods of examination and knowledge of effects generated through the work of the public auditor. Thus, the article seeks to encompass some mechanisms of assessment which may be used by these professionals, such as: situation report, questionnaire, memorandum of description and flowchart. 


\section{CONTEXTUALIZAÇÃO DA AUDITORIA}

A origem da palavra auditoria provém do latim e significa audire, ouvir. Inicialmente, como bem salienta Sá (1975, p.17), limitou-se a verificar se os registros contábeis haviam sido escriturados de forma exata. A função principal desta atividade era certificar o nível de exatidão dos procedimentos contábeis, de modo que eles expressassem, verdadeiramente, aquilo que representavam.

Corroborando neste sentido, Holmes apud Sá (1975, p. 18) cita a definição para auditoria daquele autor: "[...] a auditoria é o exame de demonstrações e registros administrativos. $\mathrm{O}$ auditor observa a exatidão, integridade e autenticidade de tais demonstrações, registros e documentos".

Ainda ratificando a mesma assertiva, Araújo (2001, p. 13) menciona que os ingleses traduziram o termo auditoria "como auditing para designar, exclusivamente, o conjunto de procedimentos técnicos para revisão dos registros contábeis".

Nos dias atuais, o conceito tornou-se mais amplo e agrega outros encargos para aqueles que desempenham as funções de auditor. Partindo deste pressuposto, Waddell (1982, p. 13), ao apresentar a natureza da auditoria, apresentou com propriedade a abrangência que se deve ter mente ao se mencionar o termo auditoria:

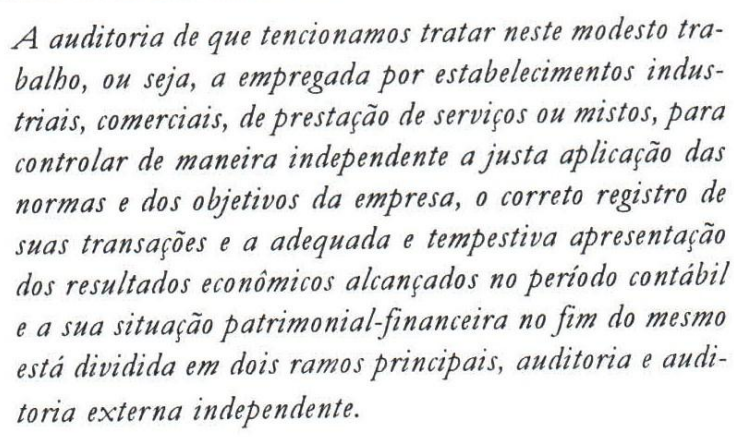

Não obstante já se encontrar consolidada a amplitude das atividades da auditoria, é válida a apresentação das disposições sobre o assunto estipendiadas pelo Conselho Federal de Contabilidade nas Normas Brasileiras de Contabilidade - NBC que encerram definitivamente a questão:

NBC T 11 - Normas de Auditoria Independente das Demonstrações Contábeis

A auditoria das demonstrações contábeis constitui o conjunto de procedimentos técnicos que tem por objetivo a emissão de parecer sobre a sua adequação, consoante os Principios Fundamentais de Contabilidade e as Normas Brasileiras de Contabilidade e, no que for pertinente, a legislação especifica.

NBC T 12 - Da auditoria interna

$A$ auditoria interna constitui o conjunto de procedimentos técnicos que tem por objetivo examinar a integridade, adequação e eficácia dos controles internos e das informaçoes físicas, contábeis, financeiras e operacionais da Entidade.

\section{ACCOUNTABILITY E O PAPEL DO AUDITOR GOVERNAMENTAL}

De acordo com o Dicionário Oxford de Língua Inglesa (2000, p. 303), o termo accountability significa responsabilidade da qual se deve prestar contas.

Para Araújo (2001, p. 1-2), ao introduzir o assunto na obra Introdução à Auditoria Operacional, não há na língua mãe vocábulo que apresente com precisão o real alcance do termo que se pretende compreender: "[....], em que pese ao esforço de alguns cultores da língua pátria em querer traduzi-la como responsabilidade, não possui uma tradução literal para o nosso idioma ou mesmo para outras línguas de origem latina".

De forma a ratificar o seu entendimento, o autor cita declaração de Anna Maria Campos que considera inexistir no pás, não a tradução de sentido para a palavra accountability, mas a essência que envolve o conceito.

Embora respeitando os posicionamentos dos autores supramencionados e acreditando que é através do embate teórico que se faz Ciência, somos de opinião distoante. No Brasil, o sentido que esses autores procuraram oferecer a accountability, a nosso ver, já se encontra no conceito de prestação de contas presente na Carta Constitucional de 1988, precisamente no parágrafo único do art. 70, verbis:

Prestará contas qualquer pessoa física on entidade pública que utilize, arrecade, guarde gerencie ou administre dinheiros, bens e valores públicos ou pelos quais a União responda, ou que, em nome desta, assuma obrigacões de natureza pecuniária.

Cremos que o trecho constitucional acima explicitado não significa tão-somente a entrega de documentos relativos a gastos da administração, gerenciamento ou arrecadação de valores públicos; vai além disto, pelas razões a seguir expostas. Primeiro, porque está inserto no procedimento governamental brasileiro de prestação de contas, a responsabilidade pelo uso (e uso correto) do patrimônio estatal (aqui incluído os valores em espécie, parcela que foi descentralizada para administração por parte de terceiros). Em segundo lugar, prestar contas em sentido amplo, é fornecer à sociedade, representada pelo Poder Legislativo, auxiliado pelo Tribunal de Contas competente, infor mações atinentes ao uso dos recursos que foram confiados aos gestores (públicos ou particulares). Daí se pode concluir que a accountability à brasileira, envolve aspectos de responsabilidade social, legal, financeira, gerencial, profissional e ética.

\section{AUDITORIA INTERNA E CONTROLE INTERNO}

À primeira vista, pode-se pensar que a auditoria interna e controle interno são termos sinônimos. De acordo com a NBC T 12, "a auditoria interna constitui o conjunto de procedimentos técnicos que tem por objetivo examinar a integridade, adequação e eficácia dos controles internos e das infor mações físicas, contábeis, financeiras e operacionais da Entidade". Em contraposição à expressão - auditoria interna - outra norma, 
também do CFC, a NBC T 11 define os controles internos como sendo um conjunto de variáveis e compreende: [...] 0 plano de organização e o conjunto integrado de método e procedimentos adotados pela entidade na protẹão do seu patrimônio, promosãa da confiabilidade e tempestividade dos seus registros e demonstrações contábeis, e da sua eficácia operacional.

Dos dispositivos normativos do CFC acima apresentados, percebe-se que a acepção que foi concebida aos "controles internos" refere-se àquela de ordem contábil. E não poderia ser diferente, vez que esta é a área para qual o auditor deve voltar a sua atenção, muito embora, em sentido amplo, controles internos tenham sentido mais vasto: envolve toda a empresa.

Para Waddell (1982, p. 16) controle interno também pode ser entendido como um conjunto de atributos. De acordo com este autor, o controle interno reside nos "organogramas e correspondentes fluxogramas e todos os métodos, procedimentos e medidas coordenadas, adotados em uma empresa".

Das conceituações mencionadas e da leitura das normas emanadas do CFC, podem-se tecer as seguintes conclusões:

a) a auditoria interna se constitui em unidade administrativa responsável pela revisão e apreciação dos controles internos, sendo portanto integrante da estrutura organizacional da empresa, companhia ou instituição. Representa o órgão encarregado de prover o acompanhamento, revisão, avaliação e/ou aprimoramento dos controles internos;

b) os controles internos, por sua vez, são procedimentos da organização - administrativos ou contábeis - relacionados à identificação de padrões de comportamento desejáveis por parte dos empregados (no caso do setor público, os servidores públicos). Através dos controles internos se consegue perceber o modus operandi como devem ser desenvolvidas determinadas ações interna corporis, isto é, a forma ideal ou a situação planejada. A tarefa do auditor em relação a estes é confrontar a situação real com a situação desejada, daí advêm os achados de auditoria.

\section{ELEMENTOSMATERIAIS PARACARACTERIZA- ÇÃO DOS CONTROLES INTERNOS}

Em tese, toda e qualquer organização possui controles internos. Mesmo nas micros e pequenas empresas, o proprietário ou o empreendedor busca identificar procedimentos básicos pelos quais os funcionários devem proceder durante a execução desta ou daquela atividade.

O simples fato de haver uma descrição, mesmo que apresentada de forma verbal em relação às atividades que devem ser desenvolvidas para o cumprimento de determinada ação, já pressupõe a existência de um sistema de controle interno.

Um exemplo característico de controle é a orientação repassada ao empregado responsável pelo caixa de uma empresa, no sentido de que ele receba o documento de venda ao consumidor, somente depois dé o mesmo ter sido conferido pelo supervisor dos vendedores. O objetivo deste procedimento é a confir mação de que a mercadoria foi vendida pelo preço correto e nas quantidades discriminadas no documento fiscal.
Com base nesta situação ilustrativa, aquilo que o pequeno empresário pretende é o estabelecimento de regras de ação, onde ele ou terceiros possam verificar se os padrões de desenvolvimento das tarefas estão sendo ou não cumpridos. A idéia central deste comando é obviamente a preservação do patrimônio da empresa, com vistas à implementação, mesmo que de forma não intencional, de um padrão mínimo de qualidade no que tange aos procedimentos em uso.

A literatura contábil impõe que os controles internos devam atender a padrões mínimos de verificação, voltados para os seguintes aspectos:

a) saivaguarća cio patrimônio;

b) prevenção de fraudes;

c) registro correto das transações;

d) promoção da eficiência operacional.

No que se refere a este último item - promoção da eficiência operacional - vale destacar a sua relevância quando da realização de auditorias de natureza operacional e de programas governamentais, onde o auditor procura avaliar os resultados alcançados, em termos de eficiência, eficácia e economicidade (art. 32 c/c o art. 70 da Constituição Federal de 1998).

\section{CONTROLES INTERNOS CONTÁBEIS X CON. TROLES INTERNOS ADMINISTRATIVOS}

A primeira tarefa que se impõe ao auditor governamental reside na avaliação dos controles internos. Aliás, esta observação já se encontra consubstanciada no item 11.2.5.2 da NBC T 11, no que se refere à natureza, oportunidade e extensão da aplicação dos procedimentos de auditoria a serem utilizados por este profissional.

E quais controles internos devem ser considerados pelo auditor? Por onde começar os trabalhos de reconhecimento dos controles existentes junto à organização pública? E se não houver controles formais, os controles informais devem ser considerados? A não existência de controles internos inviabiliza a realização da auditoria? Todas estas indagações são questões que o auditor poderia fazer logo no início dos trabalhos e que devem ser ponderadas no início de qualquer avaliação.

Em que pese o conhecimento dos controles adotados, inexiste outro caminho senão aquele da imersão na organização que se pretende auditar, para fins de conhecimento das políticas, fluxos operacionais, procedimentos adotados, sistemas infor matizados utilizados, níveis de autoridade e concepção das atribuições das unidades.

A partir deste amplo acesso à estrutura da instituição a ser auditada, o profissional da auditoria passa a ter uma visão completa do funcionamento da empresa/órgão público, e a entender melhor os seus principais aspectos:
a) atividade(s) principal(is);
b) unidades administrativas chaves;
c) nível decisório e de departamentalização;
d) existência de rotinas padronizadas; 
e) autoridades principais: funções e responsabilidades;

f) política de pessoal adotada: estrutura de cargos e salários, atribuições, contratações, promoções, lotação e rotação dos recursos humanos;

\section{g) legislação aplicável à empresa/órgão/instituição.}

O reconhecimento dos controles existentes na organização advém, tanto em decorrência desta etapa, quanto em relação às indagações formuladas pelo auditor durante esta fase, conhecida como etapa de reconhecimento. A partir deste momento, este profissional inicia o processo de identificação dos controles que afetam o patrimônio da companhia, e quais aqueles que são simples acessórios do processo operacional de funcionamento da empresa.

Direcionando nossa análise para o setor público, o auditor deverá voltar-se para os controles sobre as ações que afetam (ou poderão afetar) os resultados dos demonstrativos públicos (Balanços Orçamentário, Financeiro e Patrimonial e Demonstração das Variações Patrimoniais).

A seguir, tem-se algumas sugestões de controles correlacionados a cada uma das demonstrações públicas que poderiam ser verificados junto aos trabalhos de auditoria:

Quadro 1 - Controles correlaciondos às demonstrações públicas

\begin{tabular}{|c|c|c|}
\hline & Balanço Orçamentário & Balanço Financeiro \\
\hline $\begin{array}{l}0 \\
\mathrm{n} \\
\mathrm{n} \\
\mathrm{t} \\
\mathrm{r} \\
\mathrm{o} \\
1\end{array}$ & $\begin{array}{l}\text { a) previsão das receitas orçamentárias; } \\
\text { b) recebimento das receitas orçamentárias }{ }^{1} \text {; } \\
\text { c) fixação das despesas orçamentárias; } \\
\text { d) realização das despesas orçamentátias }{ }^{2} \\
\text { e) fixação dos créditos orçamentários adicionais }\end{array}$ & $\begin{array}{l}\text { a) fluxo de recebimento das receitas orçamentárias; } \\
\text { b) fluxo de liquidação e pagamento da despesa } \\
\text { orçamentária4; } \\
\text { c) fluxo de recebimento das receitas exta- } \\
\text { orçamentárias; } \\
\text { d) fluxo de desembolso/devolução das despesas } \\
\text { extra-orçamentárias. }\end{array}$ \\
\hline
\end{tabular}

\section{Balanço Patrimonial e Demonstração das Variações Patrimoniais}

a) saldo de caixa, bancos e contas vinculadas (FUNDEF, convênios, SUS, FPM, FPE etc.);

b) registro da incorporação de bens/direitos (bens móveis e imóveis, créditos, valores) por compra, doação, nascimento e baixa. Este último para: venda, alienação, perecimento, consumo, permuta, demolição, sinistro, inservível e incineração;

c) registro da inscrição e variação de dívidas passivas (por realização de operações de crédito, encampação, aumento por elevação da taxa cambial, aumento da dívida por correção monetária, restos a pagar, serviços da dívida a pagar, depósitos e débitos de tesouraria etc.) ou da baixa (por cobrança, cancelamento em decorrência de morte do credor etc.). controles internos. A diferença é que estes podem ser adequados ou não". Partilhamos da opinião do autor, daí porque consideramos que a existência de controles infor mais, mesmo que não rotinizados, denotam, também, a existência de controles. Cabe ao auditor, diante das peculiaridades que cercam a situação sob análise, apontar o(s) caminho(s) considerado(s) adequado(s), com vistas à correção dos controles internos considerados inadequados.

\section{. FATORES RESTRITIVOS AO CONHECIMENTO DOS CONTROLES CONTÁBEIS INTERNOS E PLANEJAMENTO DA AUDITORIA}

O entendimento do ambiente de controle da empresa ou da instituição governamental é considerado o passo inicial do planejamento da auditoria. Sem esta etapa preliminar, torna-se quase improvável a realização de uma boa avaliação dos controles internos e, indubitavelmente, poderão as etapas subseqüentes $\mathrm{da}$ auditoria vir a ser prejudicadas em termo de qualidade.

Por outro lado, existem fatores limitadores ao entendimento completo do sistema de controle. Um dos mais relevantes é aquele que considera o porte da organização: empresas com atividades diversas, com nível de departamentalização elevado, detentora de sistemas informatizados variados e com transações internacionais geram dificuldades na obtenção de entendimento completo dos fluxos operacionais existentes. A própria natureza das atividades envolvidas, por via de conseqüiência, levarão a considerações sobre o volume dos controles envolvidos, avaliação dos riscos dos controles e documentação a ser analisada.

${ }_{1}$ Relacionado à baixa dos registros no sistema orçamentário: registro contábil correto (valor, classificação do tributo, data, exercício financeiro).

2 Relacionado aos registros no sistema orçamentário: realização da licitação ou dispensa de licitação, autorização para empenhamento da despesa, emissão da nota de empenho (observar: valor, classificação contábil, histórico, dados do fornecedor - CPF, endereço, identificação completa).

3 Analisando-se a baixa de registro no sistema orçamentário, esta etapa buscaria conhecer os trâmites da receita: da arrecadação ao seu recolhimento aos cofres públicos. Seriam investigados, p. ex., se o montante recebido está correto, se a cobrança de multa/juros se refere ao exercício financeiro competente, se na data aprazada o banco/coletoria remeteu os recursos para a Secretaria de Finanças/Fazenda, se houve o registro da transação no sistema financeiro etc.

4 Além da realização dos registros no sistema orçamentário, são partes integrantes do controle: a confirmação de que os bens foram entregues e se os serviços foram prestados, na qualidade e quantidades contratadas, a análise da autenticidade do documento fiscal, a existência efetiva do fornecedor, o pagamento pelo valor contratado, o cumprimento dos prazos de entrega etc. 
Ultrapassada esta fase, e tendo o profissional de auditoria julgado suficiente o conhecimento adquirido, estará apto a iniciar a avaliação dos controles internos.

\section{AVALIAÇÃO DOS CONTROLES INTERNOS}

\subsection{Organização dos papéis do auditor:}

A natureza do trabalho deste profissional exige nível mínimo de organização dos documentos coligidos durante a auditoria (planejamento e execução).

A abertura de pasta corrente de auditoria, onde serão agregadas todas as informações e documentos considerados vitais para o exame a ser desenvolvido, é considerada um bom início. A pasta conterá os papéis de trabalho, ou seja, "o conjunto de documentos e apontamentos com infor mações e provas coligidas pelo auditor, preparados de forma manual, por meios eletrônicos ou por outros meios, que constituem a evidência do trabalho executado e o fundamento de sua opinião" (NBC T 11, item 11.1.3.1). Nesta fase preliminar poderiam ser guardadas algumas conclusões sobre:

a) aspectos detectados na estrutura hierárquica que poderão facilitar a ocor rência de fraudes, observados na visita às instalações físicas;

b) pontos de indagações realizadas que deverão ser checados posteriormente;

c) observações anotadas sobre o fluxo de pessoas em áreas chaves;

d) documentos recebidos durante a conversa com as autoridades principais (relatórios e demonstrativos) e que necessitarão de confronto com a análise de organogramas e fluxos operacionais.

\subsection{Inspeção dos procedimentos de controle}

A verificação da adequação ou não dos controles da instituição depende de algumas premissas inerentes à própria validade do controle, enquanto instrumento de aferição dos resultados pretendidos.

Embora o sistema de contabilidade e de controles internos sejam de responsabilidade da administração (NBC T 11, item 11.2.5.3), é tarefa do auditor efetuar sugestões sobre o aprimoramento destes, caso sejam detectadas imperfeições, quando da execução dos trabalhos de auditoria.

Cook e Winkle enfatizam (1983, p. 147) que um auditor independente já encara o sistema de controle interno como falho, caso não haja na organização quem execute as funções da auditoria interna. A revisão é atividade primordial do controle, com vistas à exatidão das ações executadas, de acordo com o planejamento delineado.

Objetivando examinar se os controles internos são dignos de confiança, o auditor precisa ter em mente algumas características essenciais de um adequado sistema de controle:

a) sistema de autorização: as transações devem possuir aprovações em diversas etapas ou nos pontos vitais de controle, de acordo com o nível de responsabilidade dos executores dos serviços. Ex.: Para a realização de licitação, o ordenador de despesa deverá pronunciar-se formalmente, autorizando o início do certame licitatório (art. 38 da Lei no 8666/93);

b) segregação de funções: a orientação a ser implementada é que ninguém deve ter sob sua inteira responsabilidade todas as fases inerentes a uma operação. As etapas devem ser fragmentadas, de modo que diversos setores e pessoas distintas executem somente parcela da operação. Se integrante do censo comum tal observação, para pequenas empresas torna-se mais difícil de ser visualizada em virtude das próprias características do empreendimento: número reduzido de empregados e diversidade de atribuições. No serviço público, em sentidio contrário, o que ocorre é uma fragmentação demasiada, sem que seja avaliada a necessidade deste ou daquele procedimento de controle. Ex.: o recebimento de bens do almoxarifado deve ser feito por um setor, a contabilização por outro e o pagamento por outro.

c) revisão de etapas realizadas: é importante que o procedimento implementado contemple revisões, tais como: cálculos, contagens físicas de bens e numerários etc. Exemplo aplicável à administração pública é aquele definido pela lei de licitações que possibilita ao gestor governamental a contratação de terceiro especializado para acompanhar a execução de obra pública, no tocante ao desenvolvido das diversas etapas dos serviços contratados. Com este simples procedimento, estaria sendo preservação a conferência de cálculos das medições efetuadas e a confirmação da execução dos trabalhos.

d) Limitação do acesso direto a ativos e registros: é bastante comum na área governamental o espírito interno de camaradagem entre os servidores, no tocante ao acesso a todas as áreas da instituição, cujos reflexos podem ser desastrosos para o patrimônio público. Em que pese a almoxarifados, p. ex., todo o cuidado é pouco, pois a existência de bens de fácil remoção, associado à precariedade da limitação de terceiros ao interior destas unidades administrativas, geralmente, ocasionam inexplicáveis ausências de parcela do patrimônio estatal. Além deste aspecto, a administração deve ficar alertar para a confiabilidade das informações constantes dos sistemas de registros internos, tais como: cadastros de pagamentos, sistema de administração financeira, controle de inventários, custódia de bens e empréstimos etc.

e) comparações: as comparações são úteis quando os registros são elaborados e constantemente atualizados. Em pertinência à área governamental, a defasagem com que são apresentadas as informações de natureza contábil é um empecilho de ordem quase cultural. Excetuando-se a União, através do Sistema Integrado de Administração Financeira - SIAFI e alguns Estados - cientes deste aspecto - boa parte dos municípios brasileiros ainda tem como prática a terceirização dos serviços de contabilidade que não prezam pela tempestividade da apresentação das informações contábeis. Desta forma, as comparações são podem ser efetuadas com base na escrituração, cabendo ao auditor prover-se, para elaboração de suas conclusões, mais dos levantamentos efetuados in loco, do que dos documentos que deveriam suportar o resultado da auditoria. 


\subsection{Instrumentos de análise para julgamento da eficiên- cia dos controles}

A avaliação da eficiência dos controles internos da empresa passa necessariamente pela realização de testes, com vistas ao conhecimento exato do seu funcionamento.

Florentino (1979, p. 228) propõe o julgamento dos controles internos mediante a aplicação de uma das técnicas a seguir descritas:

a) elaboração de questionário previamente preparado;

b) redação de relatório sobre como foram encontrados os controles.

$\mathrm{O}$ autor relata que a preferência vem recaindo sobre a confecção de relatórios acompanhados de levantamentos gráficos do fluxo das operações. Entretanto, ele não menciona a deficiência do processo, vez que esta avaliação percorre o tortuoso caminho da subjetividade do pesquisador, bastante influenciado pelo nível de experiência pretérita.

questionário, embora guarde também imperfeições do tipo - dificuldade na padronização, perguntas do tipo abertas versus fechadas, tabulação dos dados, sistemas de pontuações diferentes para grupos de respostas, dentre outras, possui vários aspectos positivos, tais como:

a) apresentação sistematizada de indagações;

b) diminuição da subjetividade da avaliação do auditor, tendo em vista que os roteiros são previamente discutidos e não se restringe ao poder de observação de uma única pessoa;

c) permite o aperfeiçoamento das indagações, na medida que críticas ao processo avaliativo são mais facilmente realizadas.

Abaixo apresentamos questionário de avaliação dos controles internos.

Quadro 02 - Questionário de controle interno

\begin{tabular}{|c|c|c|c|c|c|}
\hline \multirow{2}{*}{ RECEITAS ORCAMENTARIAS } & \multicolumn{2}{|c|}{ Respostas } & \multirow{2}{*}{ Observações } & \multicolumn{2}{|c|}{ Testes } \\
\hline & $\operatorname{Sim}$ & Não & & 0 & S \\
\hline \multicolumn{6}{|l|}{$\begin{array}{l}\text { 1. Existe método de previsão para cada modalidade } \\
\text { de receita própria? }\end{array}$} \\
\hline \multicolumn{6}{|l|}{$\begin{array}{l}\text { 2. Há responsável (eis) para identificar possíveis } \\
\text { causas da não realização das receitas nos moldes } \\
\text { esperados? }\end{array}$} \\
\hline \multicolumn{6}{|l|}{$\begin{array}{l}\text { 3. São realizadas revisões anuais da base de cálculo } \\
\text { das receitas? }\end{array}$} \\
\hline \multicolumn{6}{|l|}{$\begin{array}{l}\text { 4. É efetuado algum tipo de desconto pelo } \\
\text { pagamento antecipado das receitas? }\end{array}$} \\
\hline \multicolumn{6}{|l|}{$\begin{array}{l}\text { 4.1. Caso exista, o cálculo do desconto é elaborado } \\
\text { diretamente pelo agente arrecadador ou possui } \\
\text { sistema de autorização prévio junto a órgão da } \\
\text { Administração? }\end{array}$} \\
\hline \multicolumn{6}{|l|}{$\begin{array}{l}\text { 5. O pagamento ocorre junto ao próprio órgão ou é } \\
\text { realizado mediante boleto bancário? }\end{array}$} \\
\hline \multicolumn{6}{|l|}{$\begin{array}{l}\text { 6. E realizada alguma verificação dos valores } \\
\text { arrecadados em contraposição aos valores lançados? }\end{array}$} \\
\hline \multicolumn{6}{|l|}{$\begin{array}{l}\text { 7. Existem procedimentos de cobrança } \\
\text { administrativa para os valores não arrecadados e eles } \\
\text { ocorrem logo após a não realização do pagamento? }\end{array}$} \\
\hline \multicolumn{6}{|l|}{$\begin{array}{l}\text { 8. A instituição possui sistema de cobrança judicial } \\
\text { próprio ou a cobrança é feita por terceiros? }\end{array}$} \\
\hline 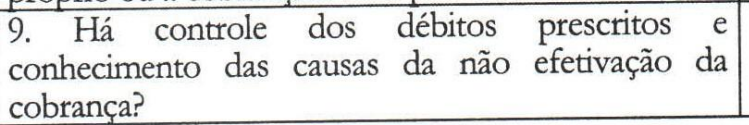 & & & & & \\
\hline
\end{tabular}

Fonte: o autor.
Tanto em uma, quanto em outra sistemática - questionário ou relatório - a percepção do auditor é preponderante em relação ao nível de confiança demonstrado pelos procedimentos de controle existentes. Assim, quanto maior a confiança apresentada pelos controles, menor será a amostra a ser coletada para a auditoria, podendo ser demonstrada em termos de relação inversa.

Além dessa forma de avaliar os controles internos, o auditor pode ainda valer-se de outros 3 instrumentos: o memorando de descrição, o fluxograma e os testes de compreensão.

Em relação ao primeiro, busca-se enumerar as atividades que envolvem uma divisão funcional importante. É comum que os regimentos internos e manuais de organização não estabeleçam com exatidão e detalhes as funções desempenhadas por cada unidade. O memorando descritivo supre esta carência, na medida que põe o auditor em contato direto com o entrevistado, de forma que ele reescreva, ao seu nível de compreensão, as operações do dia-adia do departamento, setor ou seção que se pretende avaliar.

Embora possa parecer despendioso em termo de horas empregadas, é considerado uma análise aprofundada do sistema por unidades, que agregado a análise de fluxogramas, torna-se uma ferramenta valiosa de comparação de tarefas e cruzamentos de dados.

\begin{tabular}{|c|c|}
\hline \multicolumn{2}{|c|}{ Memorando de descrição } \\
\hline Vantagens & Desvantagens \\
\hline $\begin{array}{l}\text { a) volume de informações coletadas; } \\
\text { b) permite conhecimento aprofundado } \\
\text { das atividades desenvolvidas por } \\
\text { cada unidade administrativa; } \\
\text { c) apresenta as reais atividades } \\
\text { desempenhadas; } \\
\text { d) o registro das informações pode ser } \\
\text { confirmado de imediato com o } \\
\text { entrevistado. }\end{array}$ & $\begin{array}{l}\text { a) tempo despendido; } \\
\text { b) elevação dos custos da auditoria; } \\
\text { c) não impede que informações } \\
\text { importantes sejam omitidas pelo } \\
\text { entrevistado }\end{array}$ \\
\hline
\end{tabular}

Para Oswaldo e Rocha (1987, p.98), os gráficos de fluxo ou processos, ou simplesmente fluxograma, compreende "a sequêencia lógica das fases, etapas ou passos de um trabalho desenvolvido em um escritório ou em uma área industrial, por meio de determinadas simbologias (convenções), caracterizando ainda seus agentes executores".

Através dos fluxogramas é demonstrado o e n c a d e a m e n t o seqüencial pelo qual são processadas as diversas atividades de um serviço. Possibilita a visão do desenvolvimento das fases, no seu conjunto, facilitando a análise para a 
racionalização de procedimentos, assim como a alocação de recursos humanos e materiais. Dentre as vantagens/desvantagens dos fluxogramas, sobrassem-se as seguintes:

\section{Quadro 04}

\begin{tabular}{|c|c|}
\hline \multicolumn{2}{|c|}{ Fluxograma } \\
\hline Vantagens & Desvantagens \\
\hline $\begin{array}{l}\text { a) fornece condições para simplificação do } \\
\text { trabalho, mediante a combinação, eliminação, } \\
\text { reposicionamento das etapas do trabalho; } \\
\text { b) melhor localização, correção e conseqüente } \\
\text { eliminação, para os movimentos e contatos } \\
\text { considerados desnecessários; } \\
\text { c) possibilita uma visão geral do conjunto das } \\
\text { atividades; } \\
\text { d) permite a implantação de manuais, tendo em } \\
\text { vista a distribuição ordenada das etapas do } \\
\text { serviço. }\end{array}$ & $\begin{array}{l}\text { a) requer conhecimento das simbologias } \\
\text { usuais; } \\
\text { b) exigi poder de síntese/clareza para a } \\
\text { descrição das atividades; } \\
\text { c) a simples descrição das etapas não } \\
\text { encerra as atividades de catalogação do } \\
\text { lluxograma, pois o analista deverá em } \\
\text { fase posterior estudar o fluxo, para em } \\
\text { seguida ter condições de racionalizar as } \\
\text { atividades. }\end{array}$ \\
\hline
\end{tabular}

Como já mencionado acima, há uma relação inversa entre a eficácia do sistema de controle e a extensão dos testes substantivos a serem aplicados. Quanto mais o auditor não se convencer da segurança dos registros que lhe são apresentados, mais terá que desenvolver ações de avaliação dos controles.

A Norma Brasileira de Contabilidade - NBC T 11, item 11.2.6.4 é clara ao especificar o que deve o auditor objetivar na aplicação dos testes substantivos:

a) existência - se o componente patrimonial existe em certa data;

b) direitos e obrigações - se efetivamente existentes em certa data;

c) ocorrência - se a transação de fato ocorreu;

d) abrangência - se todas as transações estão registradas;

e) mensuração, apresentação e divulgação - se os itens estão avaliados, divulgados, classificados e descritos de acordo com os Princípios Fundamentais de Contabilidade e as Normas Brasileiras de Contabilidade.

\section{ROTEIRO PARA AUDITORIA EM CONTROLES INTERNOS GOVERNAMENTAIS}

De forma a facilitar o entendimento sobre o assunto tratado, é interessante que o auditor elabore procedimento de auditoria próprio para avaliação dos controles internos. Abaixo, propomos rol de procedimentos que podem ser aplicados, tanto em uma empresa, quanto em uma instituição pública, muito embora tenha sido direcionado para esta última:

a) obter para análise, junto à instituição auditada, o regimento interno ou estatuto e o organograma do órgão/empresa pública, destacando infor mações relativas a:

- inconsistências nas atribuições das unidades referentes a pouca clareza, imprecisão, detalhamento ou concisão do texto;

- conflito de atribuições entre as unidades;

b) solicitar o quadro demonstrativo da estrutura de cargos, salários, atribuições, admissão e promoção de pessoal, e sendo este inexiste, requisitar descrição do funcionamento da política de pessoal a ser elaborada pela autoridade responsável pela contratação de pessoal;

c) requisitar os manuais de organização porventura elaborados, e não havendo estes, rotinas de controle padronizadas;

d) selecionar algumas das técnicas mencionadas adiante para descrever os controles internos detectados pelo auditor: memorando descritivo, fluxograma, questionário ou testes de compreensão;

e) agendar entrevistas com os responsáveis pelas principais unidades da organização: Presidência/Diretoria/Diretoria-geral, Contabilidade, Almoxarifado, Auditoria Interna, Orçamento e Recursos Humanos, objetivando complementar as informações sobre o sistema de controle interno da instituição, cujas infor mações foram coletadas nas fases anteriores; bilidade da ocorrência de disfunções no fluxo da operação. 
f) Inteirar-se de recomendações constantes de trabalhos similares realizados anteriormente: auditorias independentes, relatórios emanados dos tribunais de contas, controladoria, comissões de sindicância ou parlamentares de inquérito etc.;

g) Avaliar os controles internos existentes, tendo por base as observações, leituras, informações e documentos relativos aos itens precedentes constantes das letras "a/g".

\section{VISÃO GERAL DOS CONTROLES INTERNOS NO SETOR GOVERNAMENTAL E A PREVENÇÃO DE FRAUDES}

Infelizmente, a cultura reinante no país é de que os controles internos são considerados desnecessários ou burocráticos, jargão este bastante utilizado no serviço público. A falta de conhecimento sobre a Teoria Burocrática da Administração conduz a esta assertiva, ao passo que nivela os controles que funcionam com aqueles meramente protelatórios e que poderiam ser racionalizados.

Poucos gestores públicos têm o exato conhecimento da importância e da valia de um sistema de controle adequado para a segurança dos seus mandatos. Esquecem que ao final destes deverão elaborar prestações de contas dos recursos geridos, e em sendo as contas reprovadas pelo tribunal de contas competente, poderão advir inúmeros desdobrados indesejáveis: multas, afastamento, denúncia ao Ministério Público e formação de lista para encaminhamento à Justiça Eleitoral para fins de proposição das ações cabíveis.

Pela falta de um amplo conhecimento da organização dos controles, etapas desnecessárias se avolumam fazendo com que um determinado fluxo de atividades, que poderia ser minimizado, torne-se complexo e passível a fraudes.

Outro aspecto problemático, no que tange à avaliação dos controles internos, consiste na pouca clareza demonstrada pelas Unidades de Controle Interno (Auditorias Internas) sobre o que precisa ser vistoriado, tais como: fluxo de previsão e arrecadação de receitas, realização de despesas, incorporação e desincorporação de bens, direitos e obrigações, como apresentado anteriormente.

A ausência de procedimentos sistematizados para o acompanhamento dos controles é outro fator limitador nesta avaliação. As auditorias internas dos órgãos públicos optam pelo improviso, no que se refere à definição de áreas e rotinas a serem examinadas, ao passo que poderiam elaborar procedimentos de auditoria e papéis de trabalho próprios e aplicá-los com freqüência determinada.

A esta questão, associe-se como pano de fundo o fato de que os detentores das funções de "controladores" ou auditores internos ou ainda chefe do Controle Interno não são, em grande parte, portadores de diploma de bacharel em Ciências Contábeis, não obstante, a existência dos defensores da tese que qualquer profissional pode usufruir da prerrogativa de auditor interno. Neste sentido, lamenta-se o pouco entendimento do real prejuízo causado ao patrimônio público em se delegar importante atribuição a quem não detém o conheci- mento adequado e suficiente em contabilidade, berço da aplicação correta dos princípios do direito financeiro.

Por outro lado, a tão almejada independência do profissional de auditoria interna no setor público é algo que se progride passo a passo. No Poder Executivo Federal, já se menciona dispositivo que busca preservar a independência das ações do chefe da auditoria interna, mediante a sua exoneração, após apreciação do Controlador Geral da União.

Nos Poderes Legislativo e Judiciário ainda não se tem observado tal direcionamento. No Judiciário, especificamente, o chefe do controle interno é detentor de cargo/função comissionada não privativo a servidor do quadro permanente e também não goza da prerrogativa da formação profissional em contabilidade. Além disto, a nomeação passa necessariamente pelo crivo da autoridade, cujos atos de gestão serão analisados posteriormente pelo chefe da unidade de controle interno, quando da elaboração da prestação de contas anual da instituição. É o auditado nomeando o auditor, portanto, independência é algo que nestas condições não é percebida.

Destarte outros aspectos atinentes à matéria, há ainda. que se frisar que as considerações apresentadas pelo auditor ${ }^{\circ}$ governamental são vistas de forma diferente por parte dos gestores públicos, quando comparadas à gestão privada.

No setor privado, as conclusões do auditor independente são visualizadas pelo empresário, quase como que de ordem impositiva daquilo que deve ser posto em prática, sob a possibilidade da ocor rência de prejuízos ao patrimônio da empresa.

No âmbito governamental, a ótica é diferente. Como as recomendações afetam diretamente a administração daqueles que ocupam cargos públicos, interessa a estes não implementálas, pois seria o reconhecimento da culpa. Para isto as leis orgânicas dos tribunais de contas permitem, com fundamento no princípio constitucional da ampla defesa, a interposição de inúmeros recursos que objetivam retificar as decisões preliminares tomadas pelos tribunais. Durante o interregno de tempo para apreciação dos recursos, naturalmente, prevalece o sentimento de impunidade em relação aos atos praticados, e transparece para a sociedade que a ação da auditoria governamental não é eficaz.

Considerando-se que após a apreciação definitiva dos recursos poderá haver o julgamento pela irregularidade dos procedimentos de gestão que foram inquinados como ir regulares, deveriam, em tese, as impropriedades serem sanadas e a situação ser a mesma antes da prática do ato. Infelizmente, isto não ocorre com tanta ênfase na prática. Se por um lado a simples aplicação de multas, tem-se demonstrado pouco eficiente para a reparação do dano causado na extensão exata do não cumprimento da norma legal (ou a coibição de atos futuros), por outro, a cobrança desses mesmos débitos, delegada à Advocacia Geral da União, não tem gerado o ressarcimento dos valores considerados irregulares, na proporção em que foram gerados, face aos seguintes motivos:

a) valores dos débitos: de pequena monta, quando comparados com outros processos também de competência da AGU; 
b) pouca ou quase inexistência de bens para penhora, vez que entre o lapso de tempo de julgamento das contas e a ação de cobrança, muitos gestores desfazem-se dos seus bens, impedindo a efetiva ação do Poder Judiciário;

c) pouca integração entre as ações do órgão julgador com aquele responsável pela cobrança dos débitos.

Daí, pode-se concluir que a adoção de medidas de caráter preventivo, como as relacionadas abaixo, possivelmente, poderão surtir mais efeitos que a reestruturação da sistemática da auditoria governamental brasileira, que depende decisivamente da reestruturação de arcabouço legal:

a) presença do auditor interno de forma mais intensa em todas as áreas da instituição;

b) for malização dos controles internos existentes e avaliação periódica dos mesmos, com vistas ao desenvolvimento de medidas preventivas e corretivas que impeçam a proliferação de ações danosas ao Erário;

c) nomeação para os cargos/funções de auditores internos (e nomenclaturas similares) de profissionais com formação superior em contabilidade;

d) preservação da independência dos dirigentes das auditorias internas, mediante a subordinação destas unidades, inclusive a nomeação e exoneração/demissão dos detentores destes cargos, por terceiro não vinculado à entidade fiscalizada;

e) elaboração de normas próprias para a auditoria governamental.

\section{CONCLUSÃO}

A avaliação dos controles internos é atividade relevante, não somente em relação ao setor privado, quanto também nas instituições públicas.

De modo a ratificar a necessidade da existência de controles internos eficientes no setor público, o trabalho destacou a sua importância frente ao comando de prestação de contas dos recursos públicos por parte de todos aqueles que são obrigados pela norma constitucional. Por isto, as entidades governamentais necessitam estruturar unidades próprias de auditoria, ou de Controle Interno, bem como organizar procedimentos mínimos de verificação dos controles existentes.

Para que os controles internos sejam satisfatórios, devem atender a alguns aspectos mínimos de segurança: salvaguarda do patrimônio, prevenção de fraudes, registro correto das transações e promoção da eficiência operacional.

Embora nem todos os controles existentes nas organizações sejam objeto da atenção da auditoria contábil - como é o caso dos controles administrativos - o auditor governamental não segue exclusivamente esta regra, haja vista da crescente importância da auditoria de natureza operacional.
Assim como em relação à avaliação tradicional dos controles internos - objeto das instituições empresariais -, a principal preocupação do auditor governamental reside também nos atos que possam repercutir sob o patrimônio público. Por esta ótica podem ser citados como necessários, o exame dos controles relativos à: formação da receita pública, geração da despesa, incorporação/desincorporação de bens/direitos, registro e baixa de dívidas (ativa e passiva), eventos estes resultantes da execução orçamentária.

Em que pese aos fatos independentes da execução orçamentária, também pode ser verificada a consistência dos controles relativos aos créditos e débitos de natureza financeira, bem assim os registros das contas de compensação, cujos atos poderão afetar o patrimônio público em época futura.

A avaliação destes itens reside no ponto alto do trabalho do auditor. Mediante a seleção de técnicas, tais como: questionários, entrevistas, relatório, memorando de descrição, fluxograma e testes de compreensão, o auditor busca elementos de conhecimento para avaliação do funcionamento dos controles internos.

A avaliação consiste, portanto, na consolidação da opinião deste profissional, através dos elementos que são considerados decisivos para a existência de um bom sistema de controle interno: segregação de função, fluxo de autorizações, revisão de etapas, limitação do acesso direto a ativos/registros e sistema de comparações.

\section{REFERÊNCIAS BIBLIOGRÁFICAS}

ARAÚJO, Inaldo da Paixão Santos. Introdução à Auditoria Operacional. Rio de Janeiro : FGV, 2001.

ATTIE, William. Auditoria: conceitos e aplicacoôes. $3^{\text {a }}$ ed. São Paulo: Atlas, 1998.

CONSELHO FEDERAL DE CONTABILIDADE. Principios de Contabilidade e Normas Brasileiras de Contabilidade / Conselho Federal de Contabilidade - Brasília - CFC, 1999.

COOK, John William. Auditoria: filosofia e técnica. São Paulo : Saraiva, 1983. Tradução: Sônia Schwartz.

FLORENTINO, Américo Matheus. Auditoria contábil. Rio de Janeiro : Editora FGV, 1979.

MAUTZ. Roberth Kuhn. Principios de auditoria. São Paulo: Atlas, 1976. Tradução: Hilário Franco.

NORMAS INTERNACIONAIS DE AUDITORIA. São Paulo : IBRACON, 1998. Tradução: Vera Maria Conti Nogueira e Danilo A. Nogueira.

ROCHA, Luís Osvaldo Leal da. Organiząão e métodos: uma abordagem prática. $6^{2}$ ed. São Paulo : Atlas, 1987.

SÁ, A. Lopes de. Curso de auditoria. $5^{a}$ ed. São Paulo : Atlas, 1973.

WADDELL, Harold Ryne. Manual de auditoria. São Paulo: Atlas, 1982. 